\title{
Determinants of Timely Completion of Projects in Kenya: A Case of Kenya Power and Lighting Company, Thika
}

\section{Stephen Muriithi Kariungi}

Jomo Kenyatta University of Agriculture and Technology, Nairobi, KENYA

\begin{abstract}
In Kenya, the electric power supply is significantly insufficient and covers a mere $20 \%$ of the population. Experience has shown that past electric power projects have not realized the expectations in terms of their implementation and quality at entry. This study was undertaken to determine the factors that influence timely completion of power projects within Thika region. These factors were assessed from various project levels; ranging from formulation of project plans, execution, monitoring and evaluation, and closure. The factors responsible for each situation were then identified and analyzed. Research findings were based on this analysis. Descriptive and exploratory research designs were adopted. The target population was project engineers, supervisors and technical staff working in projects. The information pertaining to monitoring and evaluation came from the representatives of project financiers who included Kenya Power and Lighting Company (KPLC) staff and other reliable stakeholders. This information motivated the coverage of all the concerns in different phases of the projects.Simple random sampling was employed to identify the key informants, who were grouped based on common characteristics. Questionnaires, interviews and observation check lists were used to collect data from various respondents based on their suitability. The data collected was then coded and analyzed using SPSS. Measures of central tendency and correlation analysis were used to establish an interaction between the independent and dependent variables. Procurement delays, timely availability of funds and climatic factors were observed to be the main factors that influenced the timely completion of KPLC projects in the studied area.
\end{abstract}

Keywords: Determinants, Timely, Project completion $10 / 3 / 2014$ Source of Support: Nil, Conflict of Interest: Declared.

How to Cite: Kariungi SM. 2014. Determinants of Timely Completion of Projects in Kenya: A Case of Kenya Power and Lighting Company, Thika ABC Journal of Advanced Research, 3, 75-86.

This article is is licensed under a Creative Commons Attribution-NonCommercial 4.0 International License. Attribution-NonCommercial (CC BY-NC) license lets others remix, tweak, and build upon work non-commercially, and although the new works must also acknowledge \& be non-commercial.

\section{INTRODUCTION}

Completion of projects within schedule is a major contribution towards the competitive edge in organizations. This is based on the realization that the achievement of the targeted objectives is determined by the ability to deliver the targeted output within the stipulated time. In electrical power installation projects, different activities are involved and hence the need for 
proper management to ensure that materials and works are procured and supplied within schedule. In 2009, Kenya witnessed a significant reduction in electric power supply compared to the demand. This situation is attributed to the country's overreliance on hydroelectric power, which is greatly influenced by climatic variations. Many projects have therefore emerged with an intention of mitigating this deficit. One of such projects is Thika Power project which is expected to generate $80 \mathrm{MW}$ on its completion. It is therefore imperative that these projects are delivered in time to boast industrial and technological capacity of the region. KAM (2012) reported that ICT enabled services are some of the factors expected to foster economic development in the country.

Development partners such as the World Bank and ADB have engaged financial resources with an intention foster the growth of the industrial sector in the country. The proposed project "readiness filter" will ensure that implementation plans are timely formulated, counterpart funds and project team is identified before appraisal. Before this proposal becomes fully operational, Kenya will continue to incur high costs of power generation to deal with emergencies. KPLC Master Plan (2011) revealed that electrification ratio is significantly low with coverage of $20 \%$ of the country's population.

\section{Statement of the problem}

Kenya lies at position 115 out of 183 in terms of the time taken for electricity to be made accessible to its final consumers (KAM, 2012). Bureaucratic procedures and high unit cost due to dependency on thermal energy have been some of the factors that have discouraged new investment in the sector. Nyoike (2002) elucidates that Kenya has faced inadequate electricity generation and its supply capacity has been unreliable for over one decade. He further explains that it is only $205 \mathrm{MW}$ out of the targeted $328 \mathrm{MW}$, which was installed between 1996 and 2000. This incoherence has contributed to a major shortfall on the electricity power supply. Two IPPS were commissioned by the government in 1997 with an expected capacity of 100MW. However, the unreliable weather patterns experienced in 1999 led to an intervention through the adoption of 105MW emergency generators. This created a significant rise in the cost of electricity within the country. It is therefore important that ongoing and future projects are completed in time to help address the existing deficit between the demand and supply.

\section{Objectives of the study}

This project sought to identify the determinants scheduled project closure by identifying diverse factors ranging from planning, implementation and closure. Specifically the project assessed the project planning tools, procurement procedures, climatic factors, stakeholder analysis, managerial skills amongst project managers and timely availability of funds as possible determinants of early project completion.

\section{Literature Review}

Early project closure can be influenced by several factors. In this study, independent variables were identified and aligned the dependent variable: timely completion of projects. Although timely completion of the project is one of the determinants of its success, it is important to mange each project based on its uniqueness (Divakar \& Subramanian, 2009). Project success factors can be classified into managerial factors, efficient project planning and clarity of objectives. Enshassi, Mohamed and Abushaban (2009) identify two stages within project lifecycle as the delivery and post delivery stages. The delivery stage focuses on standard measures which involve "doing things right" while the post delivery stage is the concern of the consumers and organization to ensure that things were done right. It is based on this 
approach that "getting things right" is perceived to be more significant compared to "doing things right". Zulu and Chileshe (2008) give a comprehensive framework which entails efficiency, impact on the team, impact on the client, organizational success and preparedness for the future.

\section{Stakeholder analysis}

A stakeholder is anyone who significantly affects or is affected by another's decision pertaining to the project activities (Chevalier, 2001). It may be people or organizations who have been included or otherwise, in the process of decision making. In this study, stakeholders were entities affected by a project and therefore determined the level of success or failure of the project. Stakeholder analysis entails the identification of stakeholders, assessing their interests and the extent to which these interests affect the delivery of the project. In Kenya, policy makers, regulators, explorers, generators, suppliers and consumers are the stakeholders in power projects. The Ministry of Energy, ERC and REA are the policy makers and regulators, GDC through the IPPs, and KenGen are explorers and generators, KPLC and KETRACO are the suppliers while the general public and organizations are the consumers.

Project's success depends on its ability formulate support and management of key stakeholders. Satisfied stakeholders improve the progress and relevance of the project and hence contribute to its success (Kennon, Howden \& Hartley, n.d). Stakeholder analysis offers insights and perceptions of the relationship between the project and its stakeholders (Grimble \& Wellard, 1996).

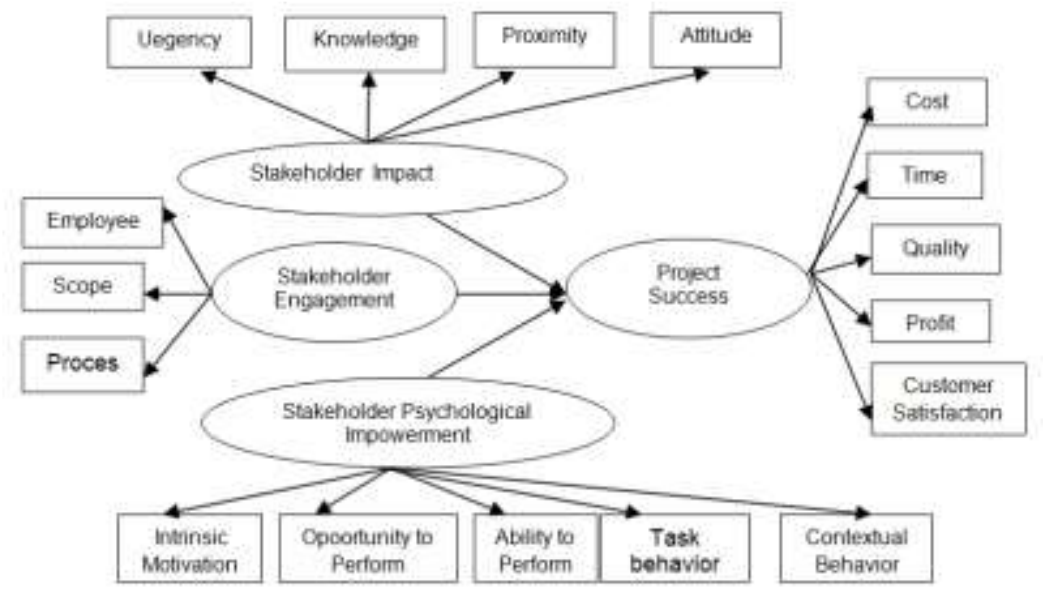

Figure 1.1: Stakeholder Influence on Project Success, Chandra, et al (2012)

\section{Managerial skills among project managers}

Kalinova (2007) convey that planning and management of a project, irrespective of its complexity require the opinions of a system based on the number of stakeholders involved. Mutual communication between these stakeholders enhances division of labour, development of individual competencies and responsibilities for effective decision making. Smallwood (2006) puts competencies into threshold or surface and differentiating or core competencies. Threshold competencies need to be practical while core competencies are yardsticks for top performers. 


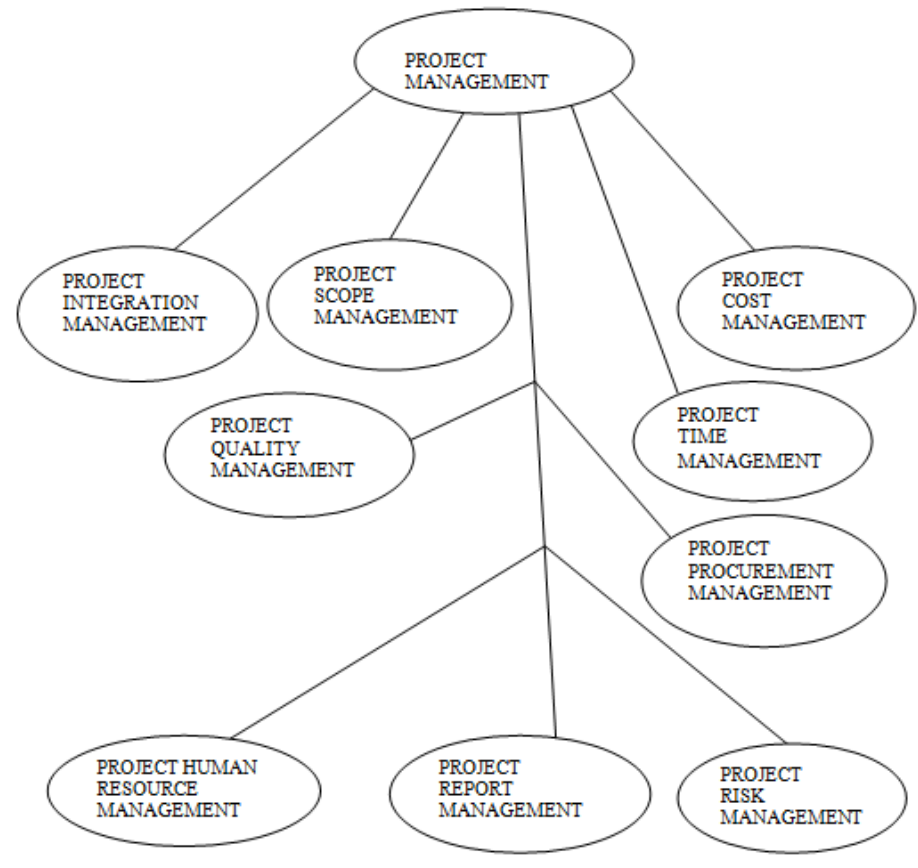

Fig 2.1 Sub-core Competency Areas under Project Management (Source, Treasury Board of Canada Secretariat, 1998)

Organizational learning theory develops managerial competencies by incorporating informal practices in the development strategy. The theory has enabled organizations to respond better to competition needs and engage more inclusive employee participation (Bitencourt, n.d). Through training individual competencies are enhanced and translated to organizational competencies. Organisational learning enhances the interaction between people, vision and pragmatic matter, which is a major challenge to organizations in their quest for competitive advantage.

\section{Procurement procedures}

Procurement is the entire process of acquiring materials, property and services required for a particular project. The process starts with the identification of need, followed by a decision on procurement requirements. The process continues through risk assessment, identification and evaluation of alternative solutions, contract award, delivery and payment of the property or service. World Health Organisation report (2007) explains that an effective procurement process ensures that materials are available at the right time, right quantity, for the right client, and at a reasonable price and quality. Ombaka (2009) further emphasizes that it does not merely entail the act of buying, but a wide range of business, operational, information technology, legal systems, safety and risk management, all undertaken to address an organisation's needs. The ability to satisfy desired needs depends on the speed at which the good is delivered; otherwise a negative externality is created on the end users.

\section{Project planning tools}

During project planning sufficient attention for establishing goals and objectives lacks; yet these are vital elements of planning. A good project plan does not necessarily lead to a good project. However, a project plan built on a weak foundation can lead to a good idea resulting 
into a poor project (Anderson, 2004). Project planning involves collection of baseline data, needs assessment, developing an action plan, implementation and evaluation. Target groups need to been well understood before goals, activities and resources required are formulated. In this study, timely completion of a project involved formal closure and transfer of lessons learnt from the project to other projects.

To enhance the understanding of project management process, the following tools are applied: project management work book and methodology, and project management guide. Carol Weiss (1995) hypothesized that the main reason for the challenges experienced by complex projects is poor articulation of the assumptions during evaluation stage. Stakeholders are uncertain about how the change process will progress and tend to pay little attention to the early and midterm changes that occur in the quest for longer term goal. Anderson (2004) postulates that clarity of the early steps needs to be undertaken towards the realization of the long-term outcome. The TOC process identifies the necessary and sufficient preconditions required to realize a certain long term outcome. Backward mapping is applied to enable the planners to think from the long term goals backwards to the intermediate and later early term changes expected to cause the targeted change.

\section{Climatic factors in power projects}

ADB (2012) proposed that electric power production and distribution infrastructure can be greatly influenced by climatic changes. Occurrences such as floods, temperature changes and intense storm surges have significant consequences on the design, construction and operation of power infrastructure. Failure to critically assess these factors makes the electric infrastructure unable to deliver the benefits they are intended for and increase the chances of project failure. Hydropower plants in Kenya have a combined installed capacity of 766.88MW. Much of this energy is generated through hydroelectric power, which is vulnerable to climatic changes. Melting of glaciers around Mt Kenya has led to the drying of rivers in the watershed (Norrington-Davies \& Thornton, 2011). This has significantly impacted on the existing projects due to the country's overreliance on hydropower. It is therefore important that the country needs to improve its capacity to deal with these forecasted changes which will significantly impact on ongoing and future projects.

\section{Timely availability of funds}

Although project delivery process does not have a stage called funding, budgetary constraints affect each stage of the process (Sullivan \& Mayer, 2010). The Right of Way to a project is not identified by a project that only fulfills the environmental process, only for the policy makers to disagree with the chosen source of funding. Mansfield et al (1994) reviewed the correlation between cost overruns and project delays and realized that a good agreement exists between the two factors.

\section{Conceptual Framework}

A conceptual framework is a detailed mental formulation of ideas that give direction to a study. It enables the interaction between dependent and independent variables to be portrayed (Kothari, 2004). In this study, the dependent variable was timely completion of projects while the independent variables were those factors that were thought to influence the realization of the dependent variable. 


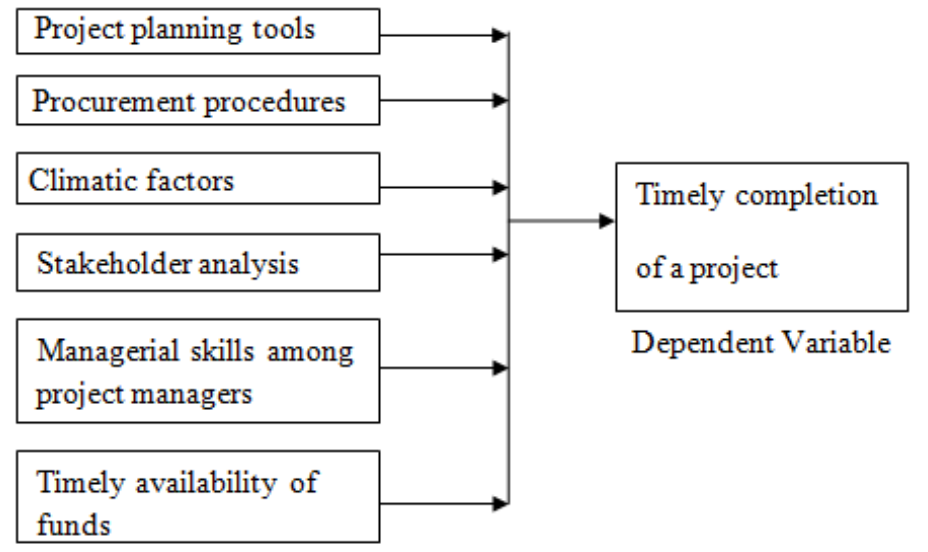

Independent Variables

Fig.3.1: Conceptual framework

\section{MetHodology}

An exploratory and descriptive research designs were adopted due to their ability to consider diverse aspects of the research problem. Literature review and experience surveys were incorporated in order to generate information relevant to the study. Survey of existing literature is a simple and fruitful procedure of formulating a research problem precisely (Kothari, 2004). A correlation analysis of the variables was sought to establish the level of interaction. This was done to determine whether a relationship existed between the variables (KIM, 2009).

Project engineers, supervisors and the technical team formed the main respondents due to their role in conceptualization, planning and implementation of projects. Probability sampling was used to identify respondents from the population. In this technique, each respondent had an equal chance of being selected. This was carried out to determine the level of significance of the findings. Probability sampling enhances the application of the Law of Statistical Regularity; which states that each sample has similar characteristics and composition (Kothari, 2004). Questionnaires were used to collect primary data from randomly selected respondents. The data obtained was supplemented with interviews and observation checklists. Snowballing and convenience sampling were adopted according to their necessity in a particular aspect (Sambasivan \& Soon, 2007).

Before dispatch, questionnaires were first tested for validity through a pilot test on the same company but in a different region. However, majority of the projects handled, were those with moderate to long project durations. This was due to realization that short duration projects lacked proper documentation during their conception and implementation. Larger sample sizes were obtained for bigger projects, due to their complexity and the number of variables to be assessed. The data collected was primarily qualitative and, was coded before being analysed using SPSS. Means were used to find the degree of agreement between variables (Faridi \& El-Sayegh, 2006). Each response was assigned a score according to the way the respondents felt that it contributed to early completion of projects. 


\section{FINDINGS}

\section{Project planning tools and their influence on timely completion of projects}

From the research findings, majority of respondents agreed that project planning needed to be improved if the challenges of late project closure are to be mitigated. A mean of 3.3, which corresponds with the response "agree to an extent", was obtained. Additionally, $75 \%$ of the respondents stated that projects were not completed within the stipulated time. However, the respondents agreed that project planning was done but adoption of planning tools was compromised during implementation. A mean of 3.7 which corresponds with "agree" on the Likert scale was obtained.

Table 1.3 Comparing projects that were initially planned and those whose planning needed improvement

\begin{tabular}{|l|l|l|}
\hline \multicolumn{3}{|c|}{ Descriptive statistics } \\
\hline & $\mathrm{N}$ & Mean \\
\hline Projects that were initially planned & 40 & 3.72 \\
\hline Projects whose planning can be improved & 40 & 3.30 \\
\hline Valid N(list wise) & 40 & \\
\hline
\end{tabular}

Procurement procedures and their influence on timely availability of materials and works in project

A correlation analysis was undertaken to determine the influence of procurement procedures on timely availability of materials and works. A correlation of 0.633 was obtained and revealed that late project closure could be attributed to procurement delays. This exhibits a moderately strong positive correlation which shows the strong influence of procurement procedures on timely completion of projects. Timely availability of materials and works has a significant impact on early project delivery.

Table 2.3 Relationship between procurement delays and project completion

\begin{tabular}{|l|l|l|l|}
\hline \multicolumn{4}{|c|}{ Correlations } \\
\hline \multirow{3}{*}{ Are there procurement delays? } & & $\begin{array}{l}\text { Are there } \\
\text { procurement } \\
\text { delays? }\end{array}$ & $\begin{array}{l}\text { Are Projects } \\
\text { Completed } \\
\text { in time? }\end{array}$ \\
\cline { 2 - 4 } & Pearson Correlation & 1 & $.633^{* *}$ \\
\cline { 2 - 4 } & Sig. (2-tailed) & & .000 \\
\cline { 2 - 4 } & $\mathrm{N}$ & 40 & 40 \\
\hline Are Projects completed in time? & Pearson Correlation & $.633^{* *}$ & 1 \\
\cline { 2 - 4 } & Sig. (2-tailed) & .000 & 40 \\
\cline { 2 - 4 } & $\mathrm{N}$ & 40 & \\
\hline **. Correlation is significant at the 0.01 level (2tailed). & \\
\hline
\end{tabular}

Timely availability of funds and its influence project time schedules

The correlation analysis carried out revealed a strong positive correlation between budgetary constraints and procurement delays. This was through a value of 0.738 which shows the existence of a strong positive correlation between the two variables. Most of the projects experienced budgetary constraints; a situation which compromised timely projects delivery. Timely availability of materials and works to a project was greatly dependent on the availability of funds. 
Table 3.3 Relationship between budgetary constraints and timely project delivery

\begin{tabular}{|c|c|c|c|}
\hline \multicolumn{4}{|c|}{ Correlations } \\
\hline & & $\begin{array}{l}\text { Do the budgetary } \\
\text { constraints lead to } \\
\text { delayed project } \\
\text { completion? }\end{array}$ & $\begin{array}{c}\text { Are Projects } \\
\text { completed in } \\
\text { time? }\end{array}$ \\
\hline \multirow{3}{*}{$\begin{array}{l}\text { Do the budgetary constraints load } \\
\text { to delayed project completion? }\end{array}$} & Pearson Correlation & 1 & $.738^{*-}$ \\
\hline & Sig. (2-tailed) & & .000 \\
\hline & $\mathrm{N}$ & 40 & 40 \\
\hline \multirow[t]{3}{*}{ Are Projects completed in time? } & Pearson Correlation & $738^{+*}$ & 1 \\
\hline & Sig. (2-tailed) & .000 & \\
\hline & $\mathrm{N}$ & 40 & 40 \\
\hline
\end{tabular}

\section{Climatic factors and their influence on timely completion of power projects}

Rainfall was revealed to be one of the critical climatic factors that delayed completion of projects in the area. Installation and construction works were delayed by unsuitable weather conditions especially during the rainy season; a situation that compromised timely project delivery. The cases of Nzuli secondary school and Mui phase II Mwingi were some of the projects that faced this challenge. High daily temperatures and rainfall slowed down the pace of activities. The critical activities affected were the way leaves and installation works. Majority of respondents agreed that climatic factors had a significant contribution to late project closure. This can be exhibited by the response 4 (agree) which had the highest frequency on the histogram below.

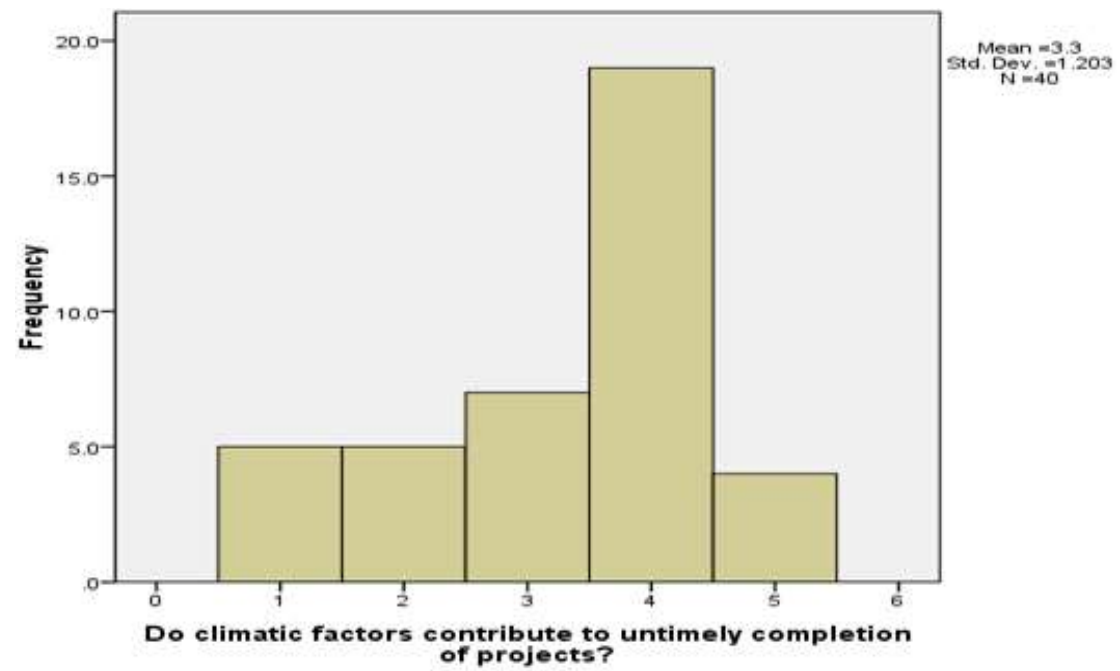

Fig 1.3: Contribution by climatic factors on project duration

\section{Influence of stakeholder analysis on timely completion of power projects}

The influence of stakeholder analysis was mainly felt in projects which took two years and above. The involvement of project consultants and financiers enhanced early planning and helped to mitigate some of the challenges anticipated. It was revealed that there was a strong positive correlation between stakeholders' engagement and early completion of projects. Fewer challenges were witnessed in those projects where stakeholders were involved from inception. A response of 4 (Yes) had the highest frequency showing that project financiers had a significant contribution to project delay. 


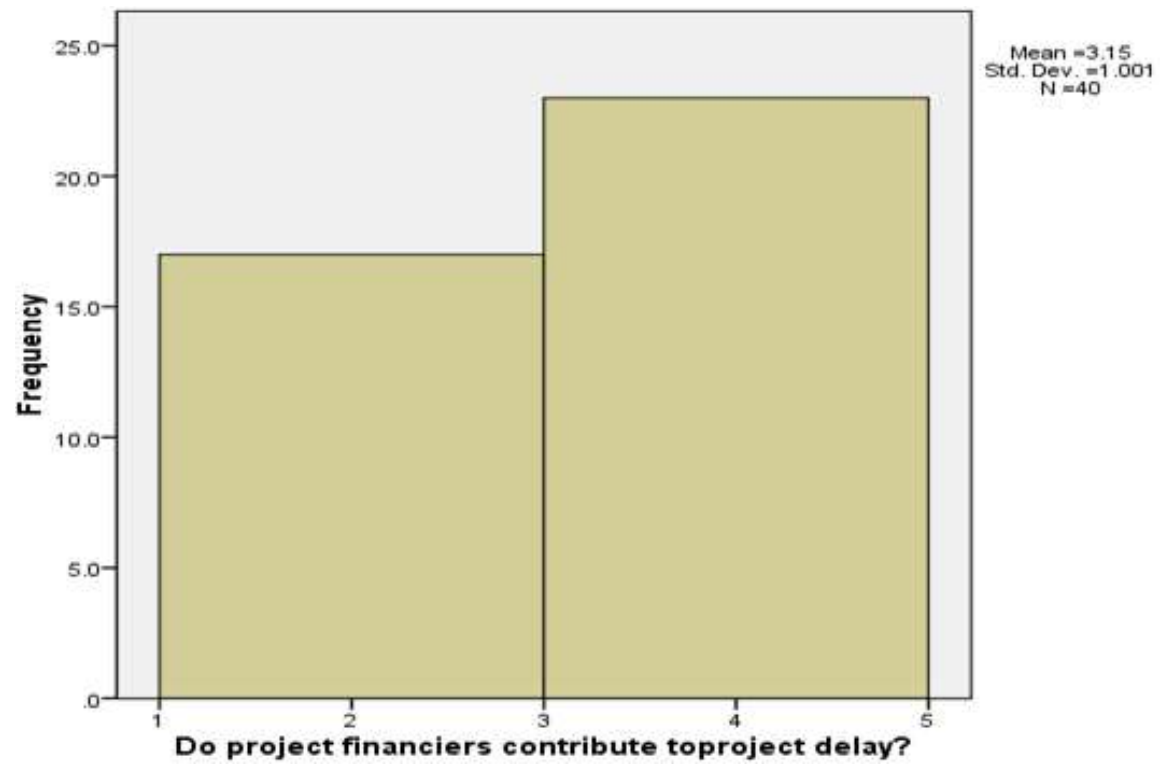

Fig 2.3: Influence of stakeholder analysis on timely project completion

Managerial skills among the project managers' and its influence timely completion of projects

The main respondents involved project engineers, supervisors and technical staff. Most of the respondents expressed that managerial skills did not pose a great challenge to projects completion in the area. The engineers were responsible for providing leadership to the project team and few challenges of lack of competency were witnessed. A response of 2 (disagree) was the mode as shown in the figure below. A mean of 2.68 which is approximately 3 revealed that the lower cadre staff was not in total agreement with the highest frequency response.

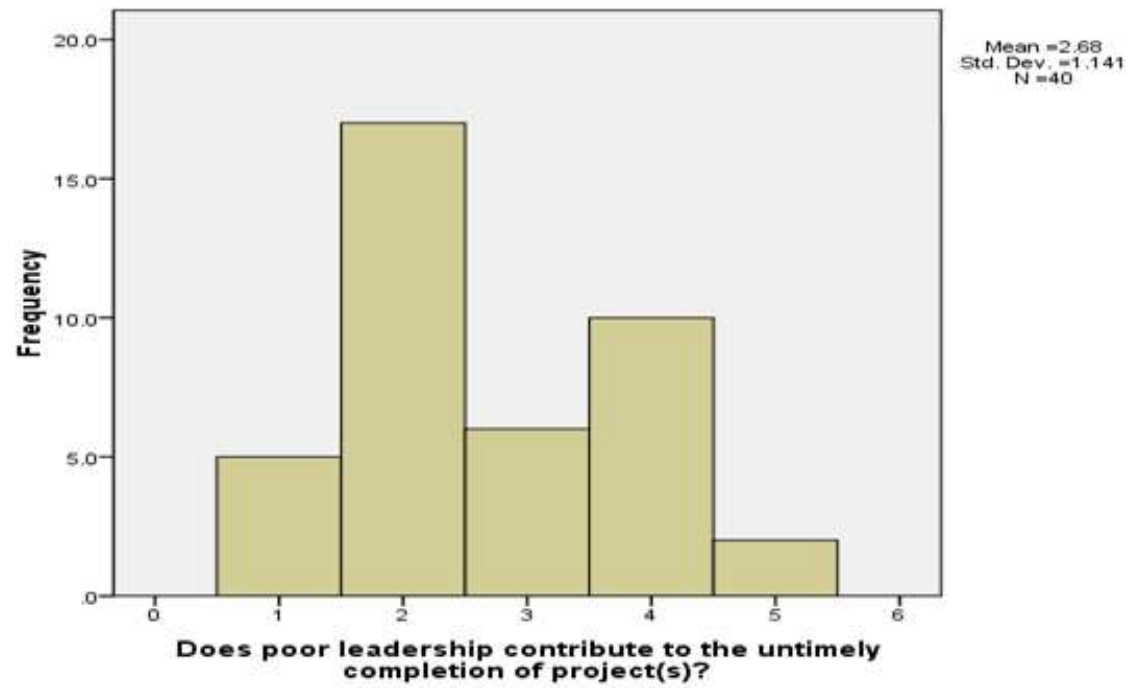

Fig 3.3: Histogram of the effect of poor leadership on project duration 


\section{Conclusions and Recommendations}

\section{Conclusions}

Timely completion of projects is a dependent variable which can be determined by several independent variables. In this study, procurement procedures, climatic factors, timely availability of funds and project planning tools were the main determinants of timely completion of projects. Procurement activities were poorly coordinated and lacked transparency, and this compromised accurate and timely delivery of materials and works; which eventually compromised the projects' duration.

Project planning tools formed the other independent variable of the study. It was revealed that collection of baseline data, needs assessment, implementation and evaluation were faced with short comings and in some projects, they were not undertaken altogether. This led to a situation where the projects failed to address the local needs and problems. It is therefore imperative that lessons learnt from these short comings be transferred to other projects to enable formal and timely project closure. The major climatic factor that affected the projects in the area and hence determined their success was rainfall. This challenge was witnessed in Nzuli Secondary School and Mui Phase II Mwingi power installation projects. Rainfall had significant consequences on the design, construction and operation of power infrastructure, making them unable to deliver the project in time and achieve the objectives they were intended for. Much of the electric power energy consumed in Kenya is generated from the hydropower plants. The recent years have witnessed a drastic change from large scale to small and mini hydropower stations due to climate variability and environmental impacts. Another challenge is that most of the potential hydro power generation sites lie in the highlands due to their undulating topography and abundant rainfall.

Availability of funds in time greatly influenced project delivery success. The Right of Way required timely commitment of financial resources, a situation which the policy makers were not able to undertake in time. Challenges of way-leaves were a major concern in Muthithi Secondary School and Githambo 132/33 KV feed outs. There also lacked a modality of 'ploughing back' resources into the ongoing projects from the ones that had been completed earlier. This would ensure that all the aspects of the project are adequately funded.

For many years managerial competencies have led to improvement in the performance of managers and leaders within organizations. Kalinova (2007) defined competence as the power of action or the ability to undertake an activity. The respondents revealed that project managers were able to discharge their duties with effectiveness; a situation which made most projects to be completed successfully. Stakeholder analysis was equally an important factor in terms of assessing the interests of various people and organizations with an intention of evaluating their concerns. The findings revealed that there were no major concerns as far as stakeholder analysis was concerned and hence less impact on the projects closure.

\section{Recommendations}

This study proposes that:

- Thermal power plants should be enhanced to mitigate the climatic effects that arise from overreliance on hydroelectric power generators.

- Project planning tools should be improved to enhance the capacity to forecast the expected project activities and their financial implications.

- Project activities need to be properly documented irrespective of the nature and magnitude of the project. This would provide information necessary for monitoring and evaluating various project challenges and hence prevent recurrence in future projects.

- Procurement procedures should be adopted according to the Public Procurement and Disposal Act 2005. 


\section{REFERENCES}

ADB, (2012). Climate Risk and Adaptation in the Electric Power Sector, ISBN 978-92 9092-730-3. Print.

Anderson, A. A. (October, 2004). Theory of Change as a Tool for Strategic Planning: A report on Early Experiences, The Aspen Institute, Round table on Community Change: New York 10010 212-6775510: $1-32$

Bitencourt, C. C. (n.d). Managerial Competence Management - The Organisational Learning Contribution, School of Management and Economic Sciences.

Chandra, H. P., Indarto, I., Wiguna, P. A. and Kaming, P. F. (2012). Model of Stakeholder Influence on project Success: An important Finding from Construction Project in east Java, International Journal of Academic Research, 4(2):1-6.

Divakar, K. \& Subramanian, K. (2009). Critical Factors to be Monitored for Successful Completion of Construction Projects, International Journal of Applied Engineering Research, 4(8): 1557-1566.

Enshassi, A., Mohamed, S. \& Abushaban, S. (2009). Factors affecting the Performance of Construction Projects in the Gaza Strip, Journal of Civil engineering and Management, 15(3): 269-280.

Faridi, A. \& El-Sayegh, S. (2006). Significant factors causing delay in the UAE construction industry, Construction Management and Economics, 24(11): 1167-1176.

Grimble, R. \& Wellard, K. (1996). 'Stakeholder methodologies in natural resource management: A review of principles, contexts, experiences and opportunities,' Agricultural Systems, 55(2): 173-193.

Kalinova, G. (2007). Project Manager and his Competencies (Knowledge, Skills and Attitude Perspectives), Slovak Journal of Civil Engineering, 2008(1): 29-36.

KAM, (2012). The KAM Industrial Business Agenda: Priority actions to build competitive local industry to expand employment in Kenya.

Kennon, N., Howden, P. \& Hartley, M. (n.d). Who Really Matters? A Stakeholder Analysis Tool, Extension Farming Systems Journal 5(2) - Research Forum (c) Copyright AFBMNetwork, http://www.csu.edu.au/faculty/science/saws/afbmnetwork/efsjournal/index.htm

Kothari, C. R. (2004). Research Methodology, Methods and Techniques (2 ${ }^{\text {nd }}$ Edition), New Age International Publishers.

Nyoike, P. (2002). 'Is the Kenyan Electricity Regulatory Board Autonomous?' Energy Policy 30: 987-997.

Norrington-Davies, G. (March, 2011). Climate Change Financing and Effectiveness: Kenya Case Study, Agulhas Applied Knowledge.

Ombaka, E. (2009). Management of Medicines Procurement in Developing Countries. Accessed online at http:/ / health-care-procurement.com/content/pdf/1689-2231-6-8.pdf.

Sullivan, M. \& Mayer, J. (2010). The Impact of Funding Issues on Project Delivery, U.S. Department of Transportation, Federal Highway Administration: 1-2.

Treasury Board of Canada Secretariat (March, 1998). An Enhanced Framework for the Management of Information Technology Projects: Project Management Core Competencies, project management Office.

Zulu, S. \& Chileshe, N. (2008). The impact of service quality on project performance: A case study of building maintenance services in Zambia, Association of Schools of Construction of Southern Africa, Cape Town: South Africa. 
Publish Online and Print Version Both

ISSN Online: 2312-203X 